Çukurova Üniversitesi Mühendislik Mimarlık Fakültesi Dergisi, 35(1), ss. 39-47, Mart 2020

Çukurova University Journal of the Faculty of Engineering and Architecture, 35(1), pp. 39-47, March 2020

\title{
Art Arda Farklı Mesafelerde Bulunan İki Binanın Akıș Analizi
}

\author{
Ahmet FERTELLi ${ }^{* 1}$, Mehmet BALTA ${ }^{2}$ \\ ${ }^{1}$ Sivas Cumhuriyet Üniversitesi, Mühendislik Fakültesi, Makine Mühendisliği Bölümü, Sivas \\ ${ }^{2}$ Amasya Üniversitesi, Teknik Bilimler Meslek Yüksekokulu, Makine Bölümü, Amasya
}

Geliş tarihi: 09.12.2019 Kabul tarihi: 15.05 .2020

$\ddot{\mathbf{O} z}$

Bu çalışmada, farklı ara mesafelerde art arda iki yerleştirilen binalar için rüzgarın etkileri üç boyutta sayısal olarak hesaplanmıştır. Sayısal hesaplamada ANSYS-FLUENT 14.0 programı kullanılmıştır. Sivas için meteorolojik veriler göz önüne alınarak ortalama rüzgar hızı belirlenmiş ve türbülans modeli olarak RNG k- $\varepsilon$ kullanılmıştır. Hesaplamalar sonucunda, binalar arasındaki mesafenin artırılmasıyla arka bina etrafindaki akış yapısı ve girdap alanlarının etkilendiği görülmüştür. Ayrıca, ilk binanın ön yüzeylerinde en yüksek pozitif basınç katsayıları oluştuğu, B, C ve D yüzeylerinde ise negatif basınç katsayılarının oluştuğu gözlenmiştir. Arka binada sadece çatı seviyesinde pozitif basınç görünüyor iken, diğer tüm yüzeylerde tüm yükseklikler için negatif basınç katsayıları elde edilmiştir.

Anahtar Kelimeler: Rüzgar yükü, Bina basınç katsayısı, Hesaplamalı akışkanlar dinamiği, Akış yapısı

\section{Flow Analysis of Two Consecutive Buildings at Different Distances}

\begin{abstract}
In the present paper, the effects of wind were calculated numerically in three dimensions for buildings placed in two consecutive different distances. ANSYS-FLUENT 14.0 program was used for numerical calculation. According to meteorological data for Sivas, the average wind speed was determined and. RNG k- $\varepsilon$ was used as the turbulence model. As a result of the calculations, it was seen that the flow structure and vortex areas around the rear building were affected by increasing the distance between the buildings. In addition, the highest positive pressure coefficients were observed on the front surfaces of the first building and negative pressure coefficients were observed on the B, C and D surfaces. In the rear building, only positive pressure was seen at the roof level, while negative pressure coefficients were obtained for all heights on all other surfaces.
\end{abstract}

Keywords: Wind load, Building aerodynamic, Building pressure coefficient, CFD, Flow structure

*Sorumlu yazar (Corresponding author): Ahmet FERTELLİ, fertelli@cumhuriyet.edu.tr 


\section{GíRiş}

Günümüzde yüksek ve birden fazla binadan oluşan, modern yaşam alanlarının sayısı artış göstermektedir. Söz konusu yaşam alanların planlaması yapılırken bina ile rüzgar etkileşimi göz önüne alınarak binalar konumlandırılmalıdır. Binalar üzerinde rüzgarlar nedeniyle oluşan farklı şiddetlerdeki basınç alanları çatı ve yüzeyler üzerinde çeşitli hasarlar oluşturabilmektedir. Ayrıca rüzgarların sebep olduğu girdap grupları, binalarda titreşim ve gürültüye de sebep olmaktadır. $\mathrm{Bu}$ olumsuz parametreler, bina konumlarının değiştirilmesi, farklı bina gruplarının yerleşim düzenleri ve bina tasarımlarının değiştirilmesi ile düzeltilebilir.

\section{2. ÖNCEKİ ÇALIŞMALAR}

Literatürdeki yapılan deneysel ve sayısal araştırmalardan, Nitinas ve arkadaşları [1], farklı 3D türbülans modellerinin geçerliliğinin sağlanması için kemerli tip, eğimli tip ve düz tip olmak üzere üç farklı çatı modeli için kontrollü hava akımı koşulları oluşturularak rüzgar tünelinde deneyler yapılmıştır. Deneysel hız ölçümleri bir Laser Doppler Anemometre ile yapılarak, çatı geometrileri üzerindeki dış hava akımı alanı ve binalar ardındaki hız dağılımı ve türbülanslı kinetik enerji dağılımları ayrıntılı olarak

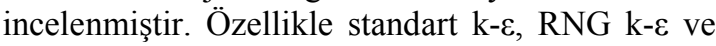
gerçekleştirilebilir $\mathrm{k}-\varepsilon \quad$ modelleri, $\mathrm{h} 1 \mathrm{z}$ dağ́lımlarında uyumlu sonuçlar elde edilmiş olup, binaların çatısında ortalama değerlerle karşılaştırıldığında daha yüksek değerler elde edilmiştir. Özmen ve arkadaşları [2], farklı çatı eğimlerine sahip binalar üzerindeki akış yapısını hem deneysel hem de sayısal olarak incelemiştir. Çatı açı eğimleri $15^{\circ}, 30^{\circ}$ ve $45^{\circ}$ olarak belirlenmiş ve yapılan analizler sonucunda çatı eğiminin $15^{\circ}$ olması durumunda emme kuvvetinin en fazla olduğu tespit edilmiştir. Rajasekarababu ve arkadaşları [3] $0^{\circ}$ ve $90^{\circ}$ iniş açılarının olduğu 300:1 ölçekli yüksek bina modeli etrafındaki akışın bir türbülans modeli kullanarak açık arazi koşulunda CFD ile çözmüşlerdir. Elde edilen çözümlemeler rüzgar tünelindeki deney ölçümleri ile doğrulanmıştır.
Sonuçlarda aşağı rüzgar etkilerinin yükseklik boyunca artan rüzgar basıncı dağılımı ile bastırıldığı görülmektedir. Rüzgar tüneli ölçümleriyle karşılaştırıldığında, rüzgar basıncı katsayılarının $\left(\mathrm{C}_{\mathrm{p}}\right)$ maksimum sapması CFD'de $\% 12$ olarak bulunmuştur. Ayrıca, CFD simülasyonu binanın genişliğine bağlı olarak ölçülen üç boyutlu bir düzlemde rüzgar akış desenlerini, yeniden dolaşımın boyutunu, uyanma ayrılma bölgelerini ve hiz profillerini göstermektedir. Wang ve arkadaşları [4] gölgelik çatılı bir binanın çatısı üzerindeki akışş şekli, rüzgar kapasitesi ve rüzgar enerjisini araştırmıştır. Farklı yükseklikler, çıkıntılar ve gölgelik tavanının eğim açıları kullanılarak bir referans binanın çatısı üzerindeki akış dağılımının oluşturduğu maksimum rüzgar potansiyeli belirlendi. Sonuçlarda düz gölgelik altında bir değişim olmadığı, çıkıntı eklendiğinde çok az değişim olduğu, üçgen gölgelik modellerinde ve eğim açısının $20^{\circ}$ olması durumunda rüzgar dağılımının en iyisi olduğu bulunmuştur. Lee ve arkadaşları [5] hedef bina etrafındaki katmanları radyal mesafelere göre belirleyerek rüzgar akışından binaların nasıl etkilendiği araştırmıştır. Kopenhag şehir merkezinde hedef bina hakkında yarıçaplar $100 \mathrm{~m}, 150 \mathrm{~m}, 200 \mathrm{~m}$ ve $250 \mathrm{~m}$ olarak belirlenerek, CFD analizinde k-türbülans modeli ile çözümlemeler yapılmıştır. Araştırma, çevre yapı katmanlarının rüzgar karakteristiği üzerinde önemli bir etkiye sahip olduğunu göstermiştir. Chen ve arkadaşları [6] yüksek katılı bir binanın, alçak katlı bir bina ile beraber yerleștirilmesi durumunda binalar üzerindeki rüzgar etiklerini araştırmak için rüzgar tünelinde rüzgar basıncı ölçümleri yapmıştır. Sonuçlarda, alçak katlı binanın yüksek katlı bina önüne yerleştirilmesi durumunda, alçak katlı binanın çatısında pozitif basınçların oluştuğunu, iki bina arasındaki mesafenin azaltılması veya yüksek binanın katsayısının artırılmasının pozitif basınç değerlerini artırdığını göstermiştir.

$\mathrm{Bu}$ çalışmada, farklı mesafedeki art arda iki bina modeli etrafındaki akış yapıları incelenmiştir. Analizler binalar etrafındaki akım çizgisi, hız vektörü ve türbülans kinetik enerji değişimlerini sunmaktadır [7]. 


\section{MATERYAL VE METOT}

Çalışma yapılan apartman her katta 4 daireden oluşan toplamda 12 katlı apartman dairesidir. Bina modellemesinde, bina boyutları $1 / 250$ oranında küçültülerek model bina $120 \times 100 \times 160 \mathrm{~mm}(\mathrm{H})$ boyutlarında tasarlanmıştır [7]. Şekil 1'de gösterildiği gibi art arda konumlandırılan iki bina ara mesafesi $\mathrm{S}_{2}$, olarak tanımlanmış $0,5 \mathrm{H}$ ve 0,75 H olmak üzere iki farklı mesafe için sayısal hesaplamalar yapılmıştır.

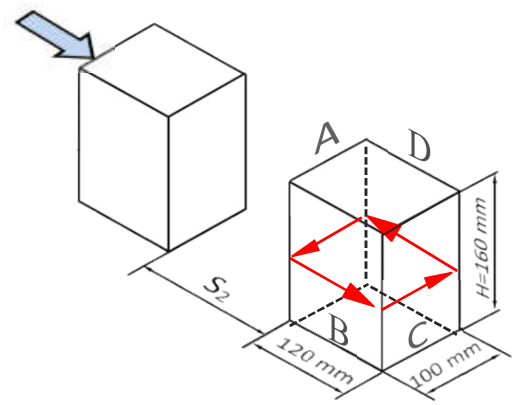

a)

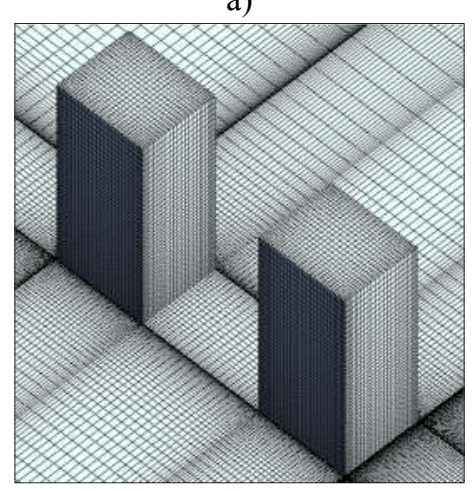

b)

Şekil 1. Bina modeli ve ağ yapısı

Analizlerde ortalama hız değeri, Sivas İli için 10 yıllık meteoroloji ortalama değerlerinden $12 \mathrm{~m} / \mathrm{s}$ olarak elde edilmiş ve Reynolds sayısı ise 179000 olarak hesaplanmıştır. Nümerik hesaplamalar için ANSYS-FLUENT 14.0 programı kullanılmıştır [8]. Üç boyutlu yapılan çözümlemelerde $S_{2}=0,5 \mathrm{H}$ mesafeli modelde 3500000 ve $\mathrm{S}_{1}=0,75 \mathrm{H}$ ara mesafeli modelde ise 3600000 dörtgen eleman (Şekil 1b) kullanılmıştır. Analizlerde akış türbülanslı olduğu için RNG k- $\varepsilon$ türbülans modeli ve Standart Duvar Fonksiyonu tercih edilmiştir.

\section{SAYISAL SONUÇLAR}

Şekil 2'de mevcut çalışma sonuçları ile daha önce yapılmış sayısal [9] ve deneysel [10] çalışmalardan elde edilen sonuçların karşılaştırılması gösterilmektedir. Bina yüzeylerindeki basınç katsayılarının dağılımlarının birbirleri ile çok yakın olduğu görülmektedir.

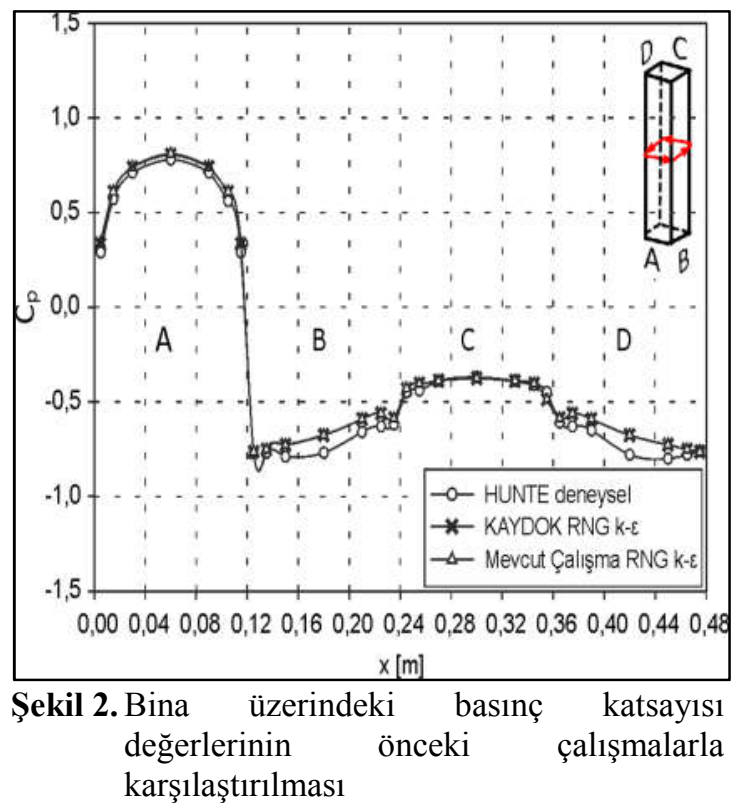

Analizler sonucunda, binanın hem orta yüksekliğinde hem de çatı yüksekliğindeki akış hareketleri elde edilmiştir ve binaların tüm yönlerde yüzeylerindeki basınç dağılımları da hesaplanmıştır.

Şekil 3'de iki bina arasındaki mesafenin $\mathrm{S}_{2}=0,5 \mathrm{H}$ olması durumunda $\mathrm{y}=80 \mathrm{~mm}$ ve $\mathrm{y}=160 \mathrm{~mm}$ yüksekliğinde akım çizgisi, hız vektörü ve türbülans kinetik enerji değişimleri sunulmaktadır. İlk binada yukarı yönlenen akış, yan yüzey duvarında girdap oluşturmuş ve bu girdap bina arkasında saat yönünde dönüş yapan girdap ile birleşince daha büyük çaplı girdap oluşmuştur. Aşağı yönlenen akış, bina yan duvarında küçük ama ters yönlü, bina arka tarafında saat yönünün tersinde dönen daha büyük ve yan yüzeydeki girdap ile birleşen girdabı oluşturmaktadır. 

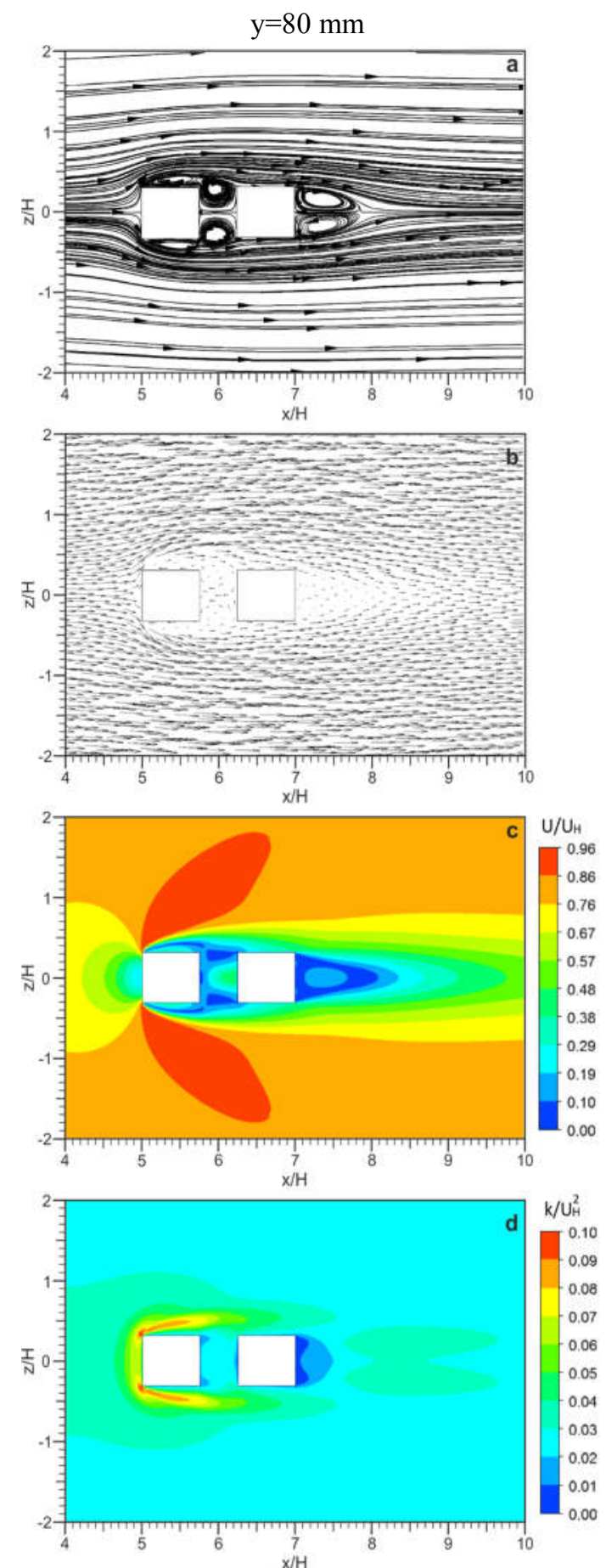
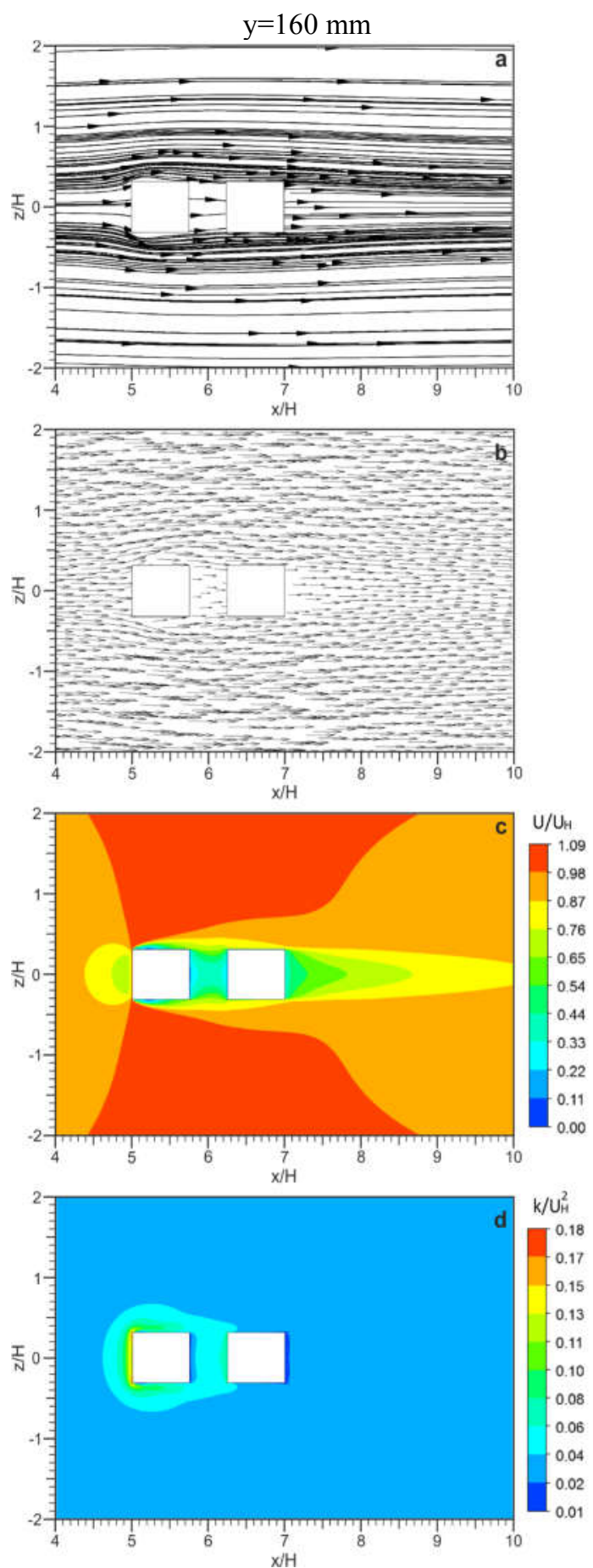

Şekil 3. $\mathrm{S}_{2}=0,5 \mathrm{H}$ mesafe için binalardaki akıs yapıları a) $\mathrm{y}=80 \mathrm{~mm}$, $\mathrm{y}=160 \mathrm{~mm}$ akım çizgisi b) $\mathrm{y}=80 \mathrm{~mm}$, $\mathrm{y}=160 \mathrm{~mm}$ hız vektörü c) $\mathrm{y}=80 \mathrm{~mm}, \mathrm{y}=160 \mathrm{~mm}$ hız d) $\mathrm{y}=80 \mathrm{~mm}, \mathrm{y}=160 \mathrm{~mm}$ türbülans kinetik enerji 

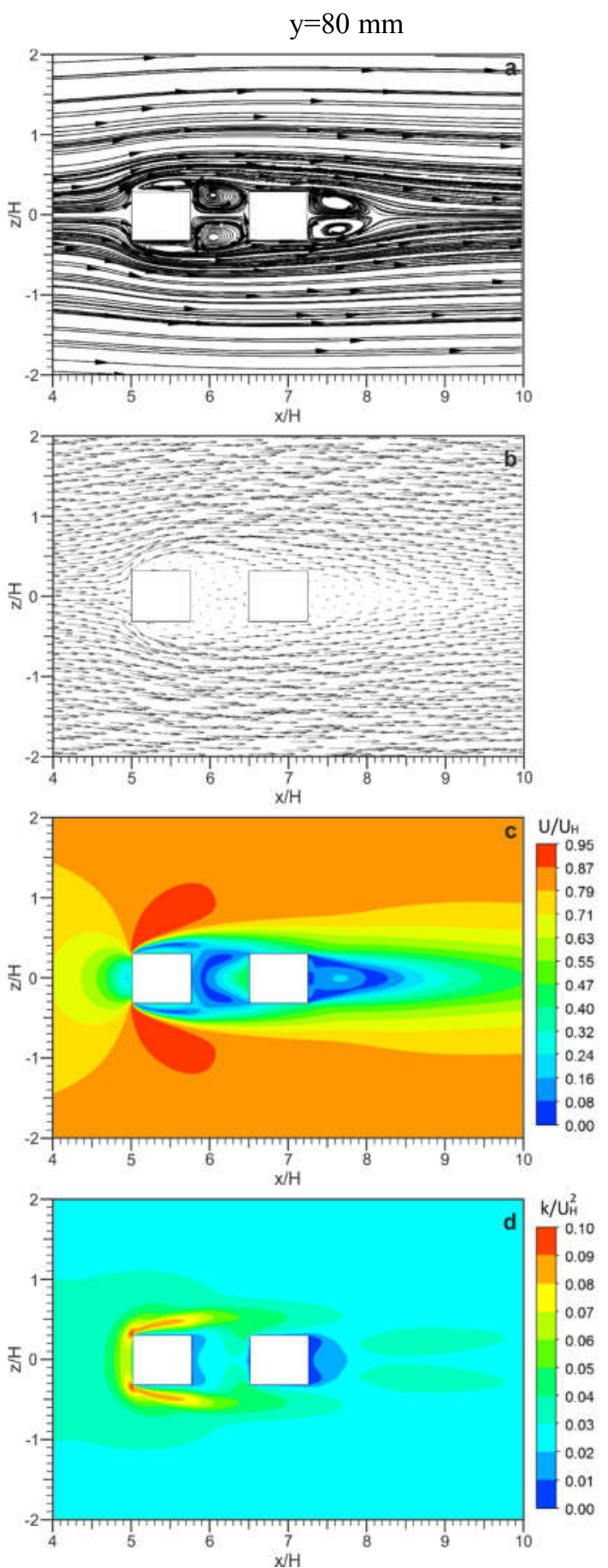
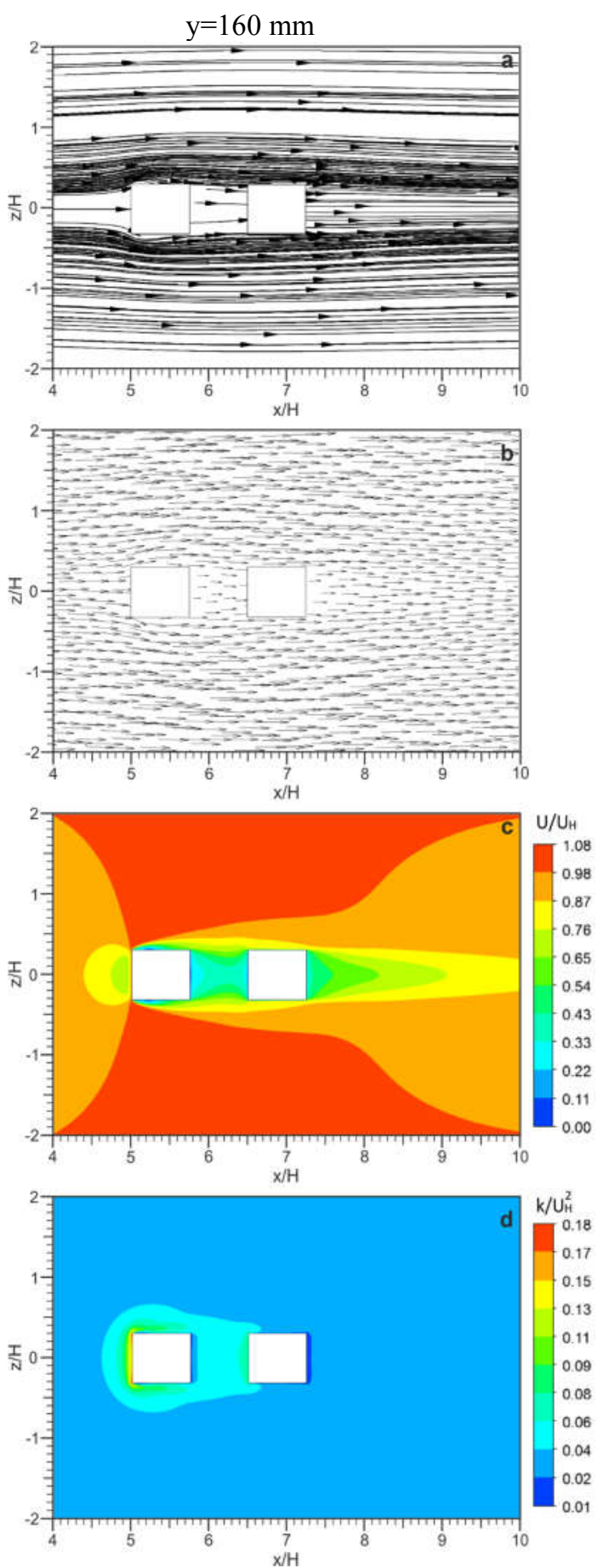

Şekil 4. $\mathrm{S}_{2}=0,75 \mathrm{H}$ mesafe için binalardaki akış yapıları a) $\mathrm{y}=80 \mathrm{~mm}$, $\mathrm{y}=160 \mathrm{~mm}$ akım çizgisi b) $\mathrm{y}=80$ $\mathrm{mm}, y=160 \mathrm{~mm}$ hız vektörü c) $y=80 \mathrm{~mm}, y=160 \mathrm{~mm} \mathrm{hız} \mathrm{d)} y=80 \mathrm{~mm}, y=160 \mathrm{~mm}$ türbülans kinetik enerji 
Görünen girdaplar birbirine simetriktir. Arkadaki binanın sadece arka bölgesinde birbirine göre ters yönde dönen simetrik iki girdap oluşmaktadır. Ön binanın yan yüzeyleri yakınında ters yönlü vektörler oluşmakta, binalar arası bölgede ve arkadaki binanın ise sadece iz bölgesinde hiz azalmaktadır. Maksimum hız ise ön binanın yan yüzeyleri üzerinde oluşmaktadır. Türbülans kinetik enerji ön binanın ön köşelerinde ve türbülanslı akışların oluştuğu yan yüzeyler üzerinde en yüksek değerlere ulaşmaktadır. Arkadaki binanın ise yan yüzeyleri üzerinde ve iz bölgesinde türbülans kinetik enerji yüksek değerlerdedir. Model yüksekliği $\quad \mathrm{y}=0,16 \quad \mathrm{~m} \quad$ seviyesinde, akım çizgilerinde ve hız vektörlerinden görüldüğü gibi her iki bina etrafında da hiçbir girdap oluşumu gözlenmemiştir. Hız dağılımından, ön bina yan yüzeyler üzerinde maksimum hızların oluştuğu ve büyük bir alanda etkisinin devam ettiği, ara bölgede her iki yükseklik için de hızlarda azalma görülmektedir. İkinci bina ilk binanın iz bölgesi sinırlarında ve bina etrafındaki hız değerleri azalmaktadır. Türbülans kinetik enerjinin en büyük değeri birinci binanın ön yüzeyinde ve çatı seviyesinde gerçekleşmiştir. İkinci binanın yan ve arka yüzeylerinde türbülans kinetik enerji değerlerinin minimum değerde olduğu görülmektedir.
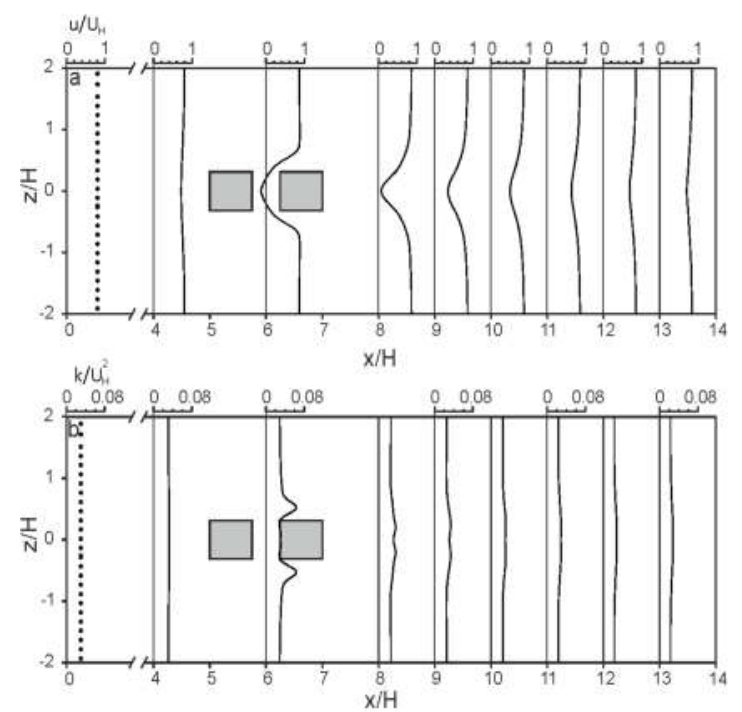

$\mathrm{S}_{2}=0,75 \mathrm{H}$ olması durumunda ise (Şekil 4) binalar arasındaki mesafenin artırılmasıyla, ön bina arakasında daha büyük saat yönünde dönen girdaplar oluşmuştur. Arka bina arkasındaki girdap şekli ve boyutlarının $\mathrm{S}_{2}=0,5 \mathrm{H}$ modeli ile hemen hemen aynı ve simetrik olduğu görülmektedir. Tüm modellerde iki bina arasındaki bölgede akış hız vektörlerinin küçüldüğü gözlenmektedir. Sadece ön binanın yan yüzeyleri yakınında ters yönlü vektörler oluşmaktadır. Ön binanın yan yüzeylerinde, binalar arası bölgede ve arkadaki binanın sadece iz bölgesinde hızların azaldığı, maksimum hızların ön binanın yan yüzeyleri üzerinde oluştuğu görülmektedir. Türbülans kinetik enerji değişimleri incelendiğinde, yan yüzeyler üzerinde en yüksek değerlere ulaştığı ve binalar arasındaki mesafenin artırılmasının türbülans kinetik enerji dağılımlarında önemli bir etkisi olmadığı görülmektedir. Model yüksekliği seviyesinde ise ilk binanın ön duvarına çarpan hava akışı binalar arkasında girdap oluşturmamıştır. İki bina arası bölgede ve arka binanın iz bölgesinde vektör boylarının küçüldüğü gözlemlenmekte, yan yüzeyler üzerinde maksimum hızın oluştuğu ve büyük bir alanda etkisinin devam ettiği, ara bölgedeki h1z değişiminin model yarı yüksekliğine kıyasla daha az gerçekleştiği görülmektedir.
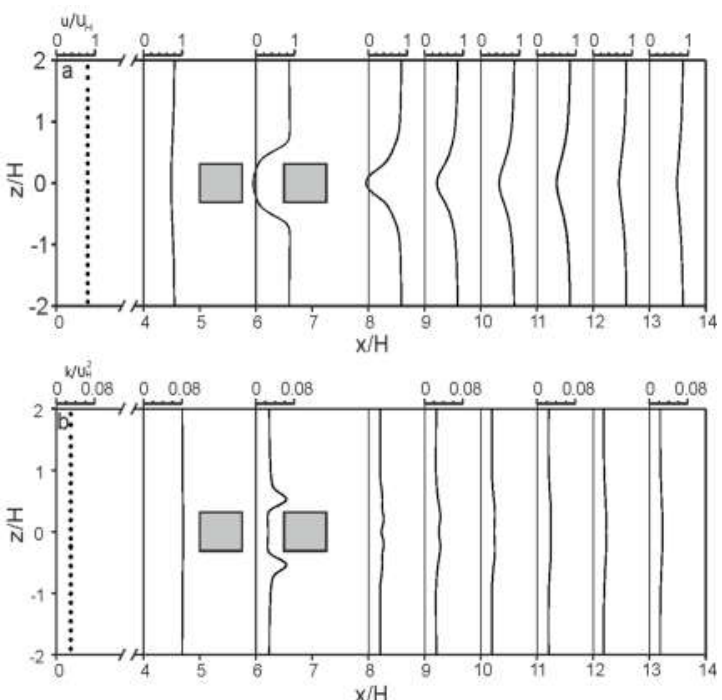

Şekil 5. $\mathrm{S}_{2}=0,5 \mathrm{H}-\mathrm{S}_{2}=0,75 \mathrm{H}$ için $\mathrm{y}=80 \mathrm{~mm}$ yüksekliğinde yatay doğrultuda a) hız profili b) türbülans kinetik enerji profili 


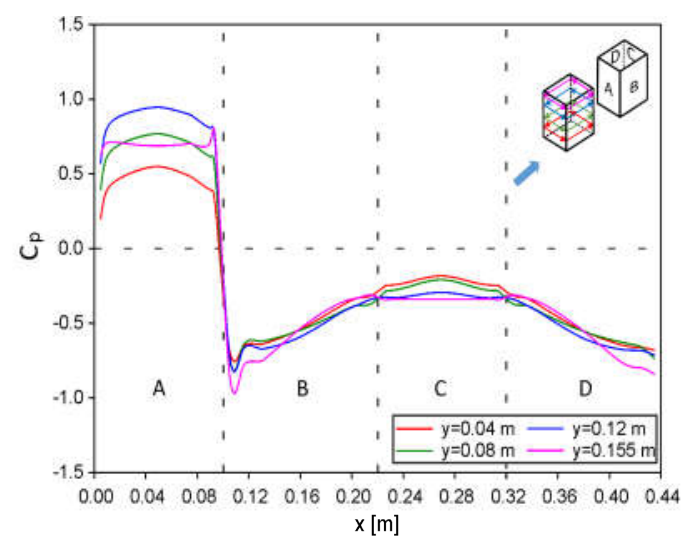

a)
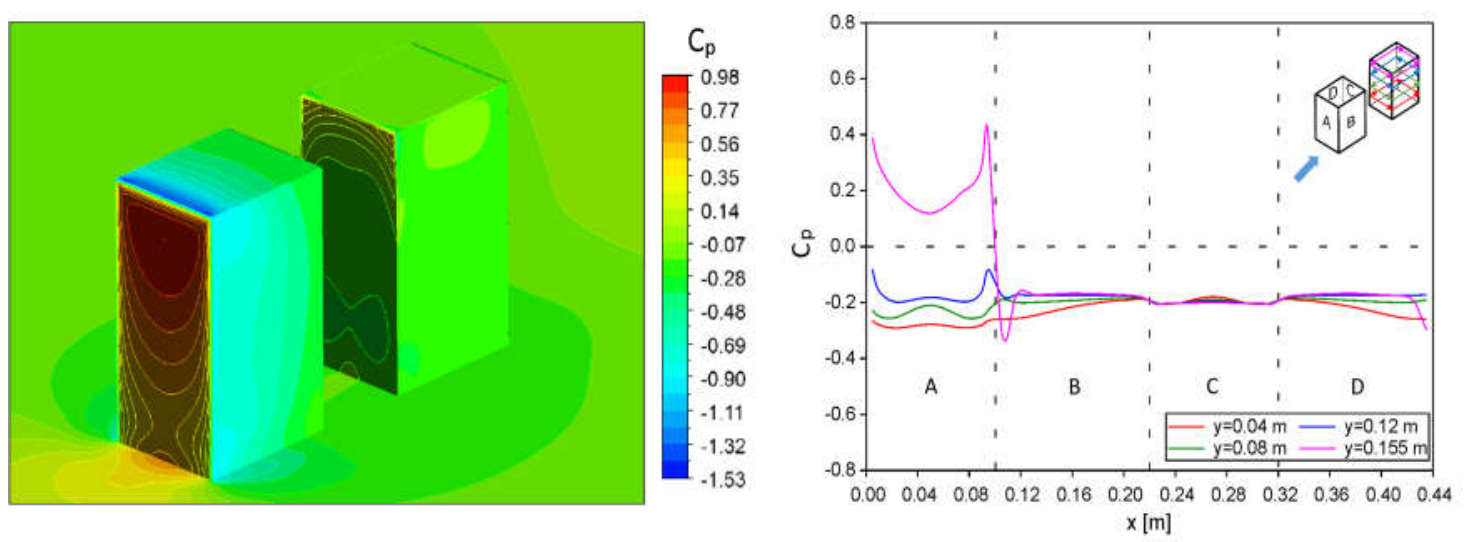

b)
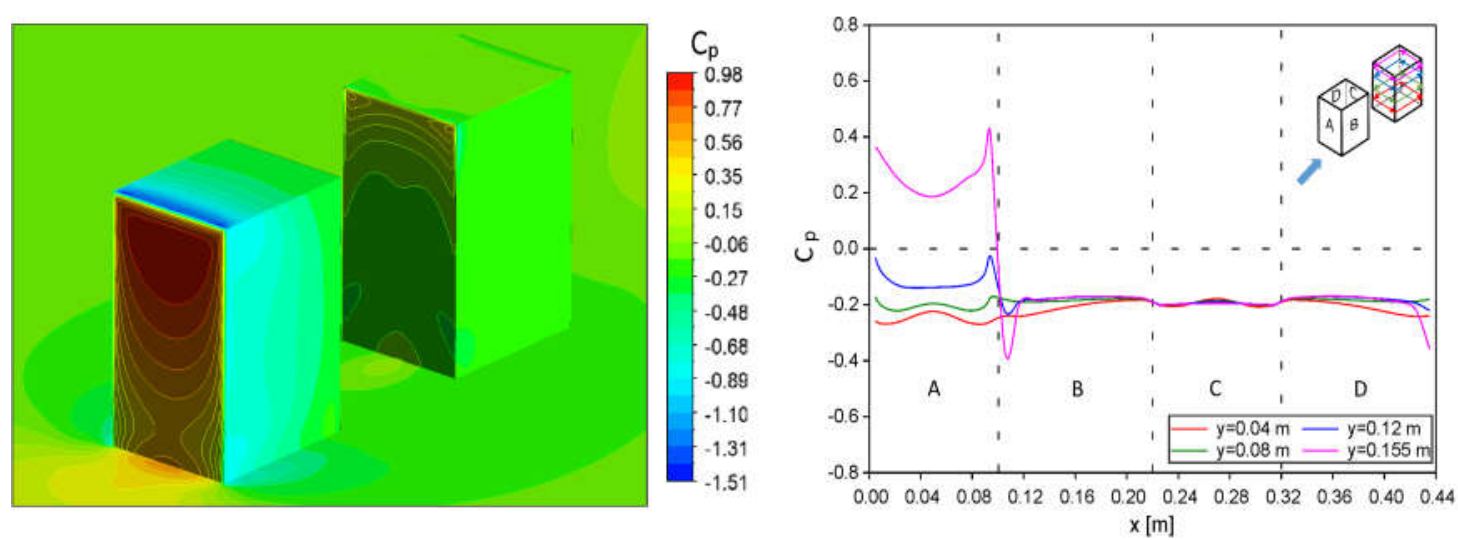

c)

Şekil 6. Bina yüzeylerinde ve farklı yüksekliklerde basınç katsayıları dağılımları, a) $\mathrm{S}_{2}=0,5 \mathrm{H}$ ön bina b) $\mathrm{S}_{2}=0,5 \mathrm{H}$ arka bina c) $\mathrm{S}_{2}=0,75 \mathrm{H}$ arka bina 
Türbülans kinetik enerji, model yüksekliği seviyesinde daha yüksek değerlerde görülmektedir. Şekil 5'de $\mathrm{S}_{2}=0,5 \mathrm{H}$ ve $0,75 \mathrm{H}$ ara mesafeli iki bina modeli arkasında, modellerinin yarı yüksekliği seviyesinde $\mathrm{y}=0,08 \mathrm{~m}$, yatay doğrultuda farklı noktalarda hesaplanan hız ve türbülans kinetik enerji profilleri gösterilmektedir. Ön bina arkasındaki iz bölgesinde hız değerleri azalmış ve ters akış bölgesi oluşmaktadır. İkinci binanın iz bölgesindeki hız değerleri azalmakta ve ters akış bölgesinin oluşumunu hızlandırmaktadır. (Şekil 5a). Akış yönünde konumlarda hızdaki azalma etkisi yok olmaktadır. Arka binanın üst ve altında türbülans kinetik enerji değerlerinde artış olurken, binadan uzaklaştıkça şiddeti azalmaktadır (Şekil 5b). $\mathrm{S}_{2}=0,75 \mathrm{H}$ ara mesafeli iki bina modeli arkasında, $\mathrm{S}_{2}=0,5 \mathrm{H}$ modeli ile karşılaştırıldığında hız ve kinetik enerji profillerinin aynı olduğu, maksimum hızın ve türbülans kinetik enerjinin arkadaki binanın hemen ön tarafinda oluştuğu görülmektedir. $\mathrm{x} / \mathrm{H}=9$ değerinden sonra $\mathrm{h} 1 \mathrm{z}$ profillerindeki dalgalanmaların ve tepe noktalarının azaldığı görülmektedir. Her iki bina modeli için $\mathrm{S}_{2}=0,5 \mathrm{H}-0,75 \mathrm{H}$ yüzeylerdeki basınç katsayıları değişimleri Şekil 6'da gösterilmektedir. A yüzeyi rüzgara doğrudan maruz kalmakta ve pozitif basınç katsayıları oluşmaktadır. Zeminden çatıya doğru yükseklik arttıkça basınç katsayıları artmakta ve çatı bölgesinde değerler azalmaktadır. Binaların iki yan (B ve D) ve arka (C) duvarlarında ise negatif basınç katsayısının mevcut olduğu gözlenmektedir. $\mathrm{B}$ yüzeyinde $\mathrm{x}$ yönünde ilerledikçe $C_{p}$ değeri artmakta, $C$ yüzeyinde hemen hemen sabit kalmakta ve D yüzeyinde ise tekrar azalmaktadır.

\section{SONUÇLAR}

Bina duvarlarındaki basınç dağılımları, rüzgar yüklerinin bina üzerinde oluşturduğu akış yapılarını, doğal havalandırma ile oluşturulan iç hava kalitesi ve iç konfor şartlarını önemli derecede etkilemektedir. $\mathrm{Bu}$ çalışmada $\mathrm{S}_{2}=0,5 \mathrm{H}$ ve $\mathrm{S}_{2}=0,75 \mathrm{H}$ mesafelerinde arka arkaya yerleştirilmiş iki bina etrafında oluşan akış yapıları ile türbülans kinetik enerji değişimleri ve basınç katsayıları hesaplanmıştır. Pozitif basınç katsayılarının binanın ön duvarında oluştuğu ve bina yüksekliği ile arttığı, arka binanın tüm yüzeylerinde basınç dağılımının yükseklikle az miktarda değişim gösterdiği tespit edilmiştir. Ayrıca, negatif basınç oluşumları hem ön hem de arka bina için yan yüzeylerde ve bina arkasında gerçekleşerek, çatı bölgesinde en yüksek düzeyine ulaşmıştır. Analiz sonuçlarından, iki bina arasındaki mesafenin arka bina üzerinde oluşan akış yapılarını ve girdap oluşumunu etkilediği gözlenmiştir. $\mathrm{Bu}$ nedenle mimari tasarımlarda binaların birbirine göre konumları belirlenirken, rüzgar hızı ve akış yapılarının da dikkatle değerlendirilmesi gerekmektedir.

\section{TEŞEKKÜR}

M-611 numaralı proje ile destekleyen Sivas Cumhuriyet Üniversitesi Bilimsel Araştırma Projeleri Koordinatörlüğü’ne teşekkürlerimizi sunarız.

\section{KAYNAKLAR}

1. Ntinas, G.K., Shen, X., Wang, Y., Zhang, G., 2019. Evaluation of CFD Turbulence Models for Simulating External Airflow Around Varied Building Roof with Wind Tunnel Experiment, Building Simulation, 12, 115-123.

2. Özmen, Y., Baydar E., Van Beeck J.P.A.J., 2016. Wind Flow Over the Low-rise Building Models with Gabled Roofs Having Different Pitch Angles. Building and Environment, 95, 63-74.

3. Rajasekarababu, K.B., Vinayagamurthy, G., Selvi Rajan, S., 2019., Experimental and Computational Investigation of Outdoor Wind Flow Around a Setback Building, Building Simulation, 12, 891-904.

4. Wang, B., Cot, L.D., Adolphe, L., Geoffroy, S., 2017. Estimation of Wind Energy of a Building with Canopy Roof, Sustainable Cities and Society, 35, 402-416.

5. Lee, D.S., 2017. Impacts of Surrounding Building Layers in CFD Wind Simulations, Energy Procedia, 122, 50-55.

6. Chen, B., Shang, L., Qin, M., Chen, X., Yang, Q., 2018. Wind Interference Effects of Highrise Building on Low-rise Building with Flat 
Roof, Journal of Wind Engineering \& Industrial Aerodynamics, 183, 88-113.

7. Fertelli, A., Balta, M., 2017. Tek ve İki Bina Etrafindaki Rüzgar Etkilerinin Sayısal Olarak İncelenmesi, Çkurova Üniversitesi Mühendislik-Mimarlık Fakültesi Dergisi, 32-3, 111-119.

8. ANSYS 14, 2011. User Guide.

9. Kaydok, T., 2014. Farklı Kesitlere Sahip Yüksek Binalar Üzerinde Türbülanslı Akışların Sayısal Incelenmesi. KTÜ Fen Bilimleri Enstitüsü, Yüksek Lisans Tezi, 94, Trabzon.

10. Hunte, S., 2010. Testing the Application of CFD for Building Design. Delft University of Technology (Master Thesis), Netherland. 
